\title{
Toilet in Transportation Vehicles: A Topic for Consideration on Travel Sanitation in Travel Medicine
}

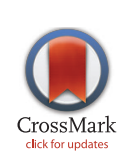

\author{
Viroj Wiwanitkit ${ }^{1,2,3,4^{*}}$ \\ ${ }^{1}$ Hainan Medical University, Hainan Sheng, China \\ ${ }^{2}$ Dr DY Patil University, Pune, India \\ ${ }^{3}$ Joseph Ayobabalola University, Nigeria \\ ${ }^{4}$ Faculty of Medicine, University of Nis, Serbia
}

Corresponding Author: Viroj Wiwanitkit, MD, Honorary Professor, Hainan Medical University, China. Email: wviroj@ yahoo.com

Received September 11, 2018; Accepted March 19, 2019; Online Published April 22, 2019

Citation: Wiwanitkit V. Toilet in transportation vehicles: a topic for consideration on travel sanitation in travel medicine. Int J Travel Med Glob Health 2019;7(3):111-112. doi:10.15171/ijtmgh.2019.23.

\section{Dear Editor,}

Toileting is a basic human activity. Human beings have to urinate and defecate as a regular daily activity to maintain a normal physiological life. During travel, urination and defecation are required, and this is usually a forgotten issue in medicine. In travel medicine, long travel and the lack of a good toilet for toileting activities are considered problematic. For example, waiting for long periods of time without the chance to go to the toilet while passing through the immigration process might be a problem for the elderly traveler. ${ }^{1}$ During long travel, the toilet in the vehicle is also an important issue.

Toilets are seen in several types of vehicles, such as the bus and the airplane. They are considered as public toilets, and concerns about them usually concern sanitation. ${ }^{2}$ Disease transmission can occur due to a dirty toilet in a travel vehicle. Toilets in airplanes require a special design for the prevention of spillage. ${ }^{3}$ Microbial contamination occurs in airplane toilets and might be a source of infectious disease transmission. ${ }^{4} \mathrm{On}$ a train, the toilet sanitation must be controlled. The design of a train toilet is also important. It must be a good design with a coat or luggage hook which is suggested to be located about 1.8 meter above the floor. ${ }^{5}$ Contamination due to droplets from train toilets is possible and can be detected at high levels at the end of a train. ${ }^{6}$ Preventing contamination becomes an interesting issue. Similar problems are also observed in a bus toilet. Intestinal parasitic contamination is detectable in buses with toilets. ${ }^{7}$ Finally, a similar problem has also been reported for toilets on cruise ships. To provide good toilet facilities is mentioned as a way to prevent the problem of food-borne infectious diseases relating to cruise trips. ${ }^{8}$ Regular cleaning of the toilets is needed. In a recent study, only one-third of cruise ship toilets received proper daily cleanings. ${ }^{9}$

The issue of toilets in transportation vehicles is an important but forgotten issue. Usually, no one specific person is assigned to deal with this public health issue. The role of the travel medicine specialist as regards the sanitation control of toilets in transportation vehicles should be promoted.

\section{Conflict of Interest Disclosures}

The author declares that he has no conflicts of interest.

\section{Ethical Approval}

Not applicable.

\section{Funding/Support}

None.

\section{References}

1. Meesit A, Kaewla W, Wiwanitkit V. Forgotten problems in land border crossings. Ann Trop Med Public Health. 2016;9(2):130131. doi:10.4103/1755-6783.177388.

2. Cynthia K, Short M, San Filippo B. Promoting safe hygiene practices in public restrooms: a pilot study. J Environ Health. 2014;77(4):8-12.

3. Lacey SE, Abelmann A, Dorevitch S. Exposure to human waste from spills while servicing aircraft lavatories: hazards and methods of prevention. Ind Health. 2010;48(1):123-128. doi:10.2486/ indhealth.48.123.

4. Zhao B, Dewald C, Hennig M, et al. Microorganisms @ materials surfaces in aircraft: Potential risks for public health? - A systematic review. Travel Med Infect Dis. 2019;28:6-14. doi:10.1016/j. tmaid.2018.07.011.

5. Loth M, Molenbroek JFM, van Eijk DJ. Hand luggage in the train toilet. Work. 2018;59(3):387-399. doi:10.3233/wor-182689.

Copyright $\odot 2019$ The Author(s). This is an open-access article distributed under the terms of the Creative Commons Attribution License (http:// creativecommons.org/licenses/by/4.0), which permits unrestricted use, distribution, and reproduction in any medium, provided the original work is properly cited. 
6. Nikodemusz I, Vedres I, Balatoni M. [Microbial contamination of railroad trains]. Zentralbl Bakteriol Mikrobiol Hyg B. 1988;187(1):70-74.

7. Borges CA, Costa-Cruz JM, Paula FM. Intestinal parasites inside public restrooms and buses from the city of Uberlandia, Minas Gerais, Brazil. Rev Inst Med Trop Sao Paulo. 2009;51(4):223-225. doi:10.1590/S0036-46652009000400009.

8. Lew JF, Swerdlow DL, Dance ME, et al. An outbreak of shigellosis aboard a cruise ship caused by a multiple-antibiotic-resistant strain of Shigella flexneri. Am J Epidemiol. 1991;134(4):413-420. doi:10.1093/oxfordjournals.aje.a116103.

9. Carling PC, Bruno-Murtha LA, Griffiths JK. Cruise ship environmental hygiene and the risk of norovirus infection outbreaks: an objective assessment of 56 vessels over 3 years. Clin Infect Dis. 2009;49(9):1312-1317. doi:10.1086/606058. 